\title{
Fuzzysmc based Speed Control of BLDC Motor
}

\author{
Priyanka Bharat More \\ Post graduate student, \\ Department of Electrical Engineering \\ AISSMS College of Engineering \\ Pune, India
}

\author{
Dr. A. A. Godbole \\ Assistant Professor, \\ Department of Electrical Engineering \\ AISSMS College of Engineering \\ Pune, India
}

\begin{abstract}
DC motors are popular in industry. Owing to benefits like higher starting torque, variable speeds with varying input voltage and cheaper to control than $\mathrm{AC}$ but they suffer from certain drawbacks due to the presence of commutator and brushes. On the other hand, a BLDC motor doesn't have commutator and brushes and therefore has many advantages over normal de motor. BLDC motor has very vast speed range but its speed control is difficult. In literature, there are many control techniques reported to control speed. This paper presents FUZZYSMC based speed control of BLDC motor, by combining the beneficial features of both sliding mode control and fuzzy logic. This design is compared with PI controller. MATLAB Simulink model is developed for both the control strategies for different loading conditions. System is tested for various parameter changes and accordingly speed response is observed. From simulation it is evident that, FUZZYSMC controller is better than PI controller in terms of rise time, settling time etc.
\end{abstract}

Keywords-BLDC motor; sliding mode control; fuzzy logic;PI controller

\section{INTRODUCTION}

A brushless dc motor is a permanent magnet synchronous motor that has trapezoidal back emf. It possess same characteristics as that of dc motor. Due to absence of brushes and commutator, BLDC motor has many benefits than DC motor, such as high efficiency, faster acceleration, no sparking, less maintenance and longer life. For commutation purpose rotor sensors are employed. Speed control is very important part in BLDC motor. It can be done by using different controllers like PI [16], PID [2], and SMC [14], FUZZY [15] etc. Most popular of these controllers is PI controller.

The control system used for regulating speed should ensure that the steady state error is small and the transient response is also satisfactory. The speed of motor is largely affected by varying load conditions. It is thus the duty of a controller to maintain the speed regulated to the desired value. As the load on the motor changes, the PI controller parameters are needed to be retuned to give the same performance. However, a robust control like Sliding Mode is able to deliver the same performance in the event of changing load conditions. This paper presents combination of FUZZYSMC controller which takes into account advantages of both fuzzy and SMC, and makes easy operation of BLDC motor for various speeds. It is then compared with conventional PI controller.

\section{VSI FED BLDC MOTOR}

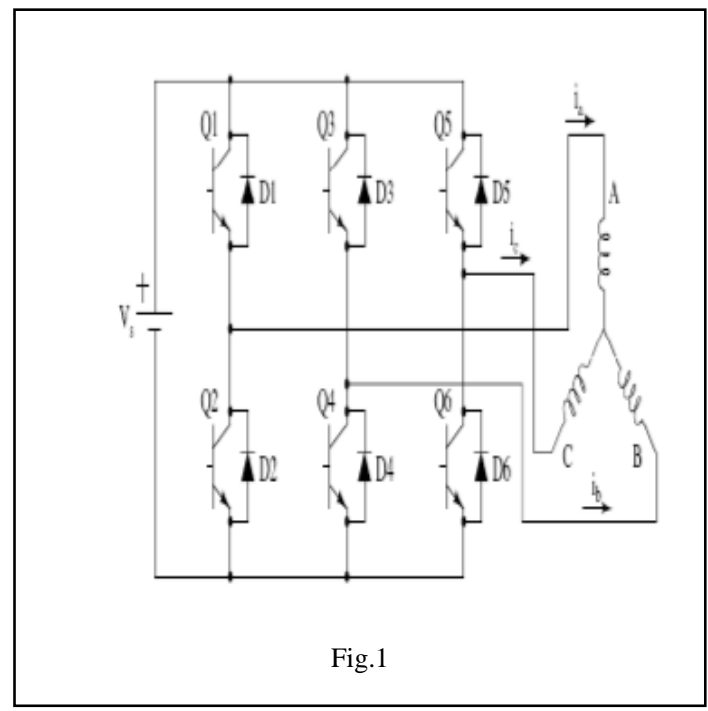

A brushless dc motor with voltage source inverter is shown in fig (1).For commutation purpose rotor sensors are employed. According to rotor position, coils are energized in specific sequence to run the motor [2].

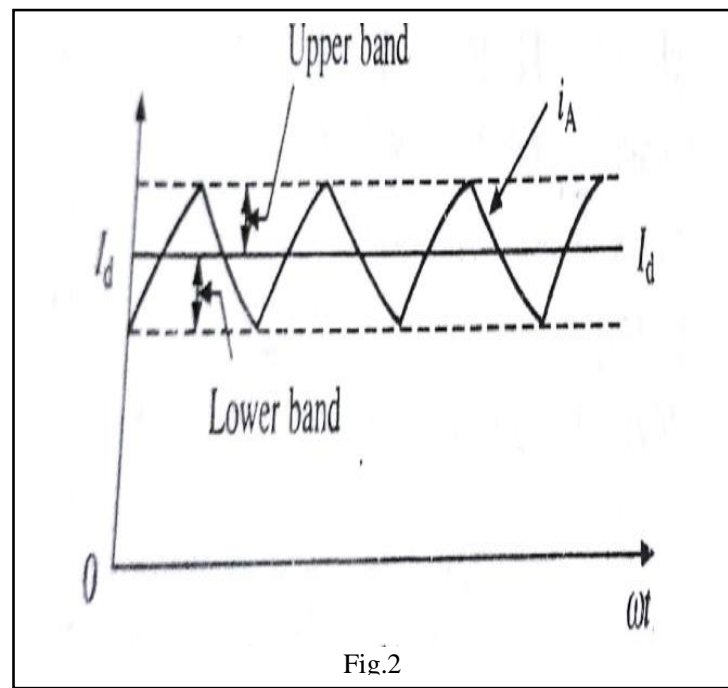

The stator winding current pulses are shown in Fig. (2). Currents are placed where EMF induced is greatest and constant [11]. By way of alternative turning on and off the thyristors, stator current follows the reference current. According to faradays law of electromagnetic induction, there is interaction between permanent magnet rotor flux and flux produced by stator coil, which forms torque. This torque shifts 
rotor to new position and switching pattern of inverter is altered and hence new torque is produced, hence motor runs continuously in same direction [3].

\section{MODELLING OF BLDC MOTOR}

Three phase BLDC motor works in two phase. Signals from Hall Effect sensors are modified after every 60 degree [2]. The flux allocation is nonsinusoidal.Hence the brushless dc motor can be designed by using phase variables. The derivation of mathematical model is based on assumption that stray losses and currents due to stator harmonics are neglected [1]

$$
\begin{aligned}
& V_{a}=i_{a} R+\left(L_{a}-M\right) \frac{d i_{a}}{d t}+E_{a} \\
& V_{b}=i_{b} R+\left(L_{b}-M\right) \frac{d i_{b}}{d t}+E_{b} \\
& V_{c}=i_{c} R+\left(L_{c}-M\right) \frac{d i_{c}}{d t}+E_{c}
\end{aligned}
$$

By assuming that all three phases are symmetrical, their selfinductance and mutual inductances are equal to each other, we write equations 1-3 in matrix form as follows:

$\left[\begin{array}{l}V_{a s} \\ V_{b s} \\ V_{c s}\end{array}\right]=\left[\begin{array}{ccc}R_{S} & 0 & 0 \\ 0 & R_{s} & 0 \\ 0 & 0 & R_{S}\end{array}\right]\left[\begin{array}{c}i_{a s} \\ i_{b s} \\ i_{c s}\end{array}\right]+\left[\begin{array}{ccc}L-M & 0 & 0 \\ 0 & L-M & 0 \\ 0 & 0 & L-M\end{array}\right] P\left[\begin{array}{l}i_{a} \\ i_{b} \\ i_{c}\end{array}\right]+\left[\begin{array}{l}E_{a} \\ E_{b} \\ E_{c}\end{array}\right]$

Where Rs is stator resistance

$\mathrm{L}$ is self-inductance per phase

$\mathrm{M}$ is the mutual inductance

$\mathrm{E}$ is back EMF

$\mathrm{P}$ is derivative operator

The equation of motor torque is given by,

$T=J \frac{d \omega}{d t}+B \omega-T_{L}$

Where,

$\mathrm{T}$ is torque developed in $\mathrm{N}-\mathrm{m}$

$\omega$ is mechanical rotor speed in $\mathrm{rad} / \mathrm{sec}$

$\mathrm{T}_{\mathrm{L}}$ is load torque in $\mathrm{N}-\mathrm{m}$

$\mathrm{J}$ is moment of inertia

$\mathrm{B}$ is friction coefficient

\section{FLOW OF WORK FOR SPEED CONTROL}

Gating signals are changed according to rotor position. Rotor speed is compared with reference speed, which is sensed by Hall Effect sensors and error is provided to the controller. It may be PI or FUZZYSMC. The error obtained is given to the controller. The controller then controls the DC voltage which is fed to the inverter, and speed is controlled accordingly.

\section{SLIDING MODE CONTROLLER}

Sliding mode control is very popular and robust control system for nonlinear systems [9]. Sliding mode control is discontinuous control scheme in which the control signal is switched at a very high frequency to achieve robustness against system uncertainties [9]. Sliding mode controller design involves two steps. The first step is to design stable sliding surface and the second one is to find a control law which forces the state trajectories to converge to sliding surface.

The is a user designed surface is named as sliding surface and is given by,

$$
S=\dot{\mathrm{e}}+\beta_{1} e+\beta_{2} \int e d t
$$

Where $\beta$ 1 and $\beta$ 2 are surface parameters and they decide the rate of convergence of error. Values of these parameters are real and positive [2]. The control law is given by,

$$
u=-k \operatorname{sign}(S)
$$

Where $\mathrm{S}$ is switching surface defined in equation (5).

$\mathrm{k}$ is constant which depends upon the bound of uncertainty. sign (.) is signum function

This control law works, if following condition is satisfied:

$$
s \dot{s} \leq \lambda|s|
$$

Where $\lambda$ is positive constant used to ensure that system trajectory reaches sliding surface in specified time. Sliding mode control has its own disadvantages. This technology requires information about the bound of uncertainty. A larger value of bound results in large control and also increases chattering. Chattering is nothing but high frequency oscillations in the output, which can cause wear and tear of motor.

\section{FUZZY LOGIC}

Just like SMC, fuzzy logic control is also used for BLDC motor speed control. Fuzziness is nothing but inadequacy of an event [10].The system in which parameters are unknown or imprecise uses fuzzy logic. In fuzzy logic there is universe of discourse, where number of objects are collected.i.e it is entire object of discussion [10].A universe of discourse and membership function that comprises of all the universe is called as fuzzy sets. Fuzzy logic includes some linguistic variables, some rules for inference and some membership functions. Membership functions describes fuzziness of a fuzzy set [10]. If its value is zero then that element is not in the fuzzy set. If the value is in between 0 and 1 then corresponding element lies in fuzzy set. There are various types of membership function like trapezoidal, triangular, bell type, Gaussian etc. Out of all methods, trapezoidal and triangular are commonly used. It is very simple and effective method used for linear and nonlinear system. It gives fast and reliable operation. It has three steps fuzzification, inference and defuzzification and some predetermined rules [10]. By changing rules, one can change the system control accordingly. 


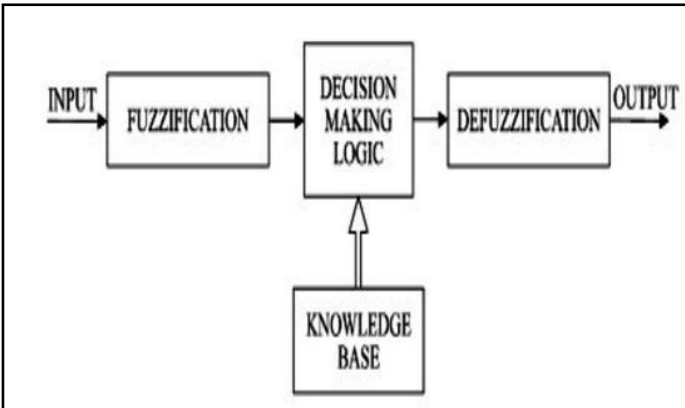

Fig.3 Fuzzy Logic Controller

\section{SMCFUZZY}

SMC and FUZZY both have their own advantages and disadvantages. So by combining FUZZYSMC we will give finer results. To obtain the optimum value of the uncertainty bound, we have used fuzzy technology. It is then observed that this method of combining fuzzy logic and sliding mode has reduced chattering considerably. The gain $\mathrm{k}$ in the control law of sliding mode controller is controlled by employing fuzzy logic [2]. The sliding surface and its derivative is the input to the fuzzy logic controller while output is control gain ' $k$ '. Here in this paper, control is to be carried out by using triangular membership function.

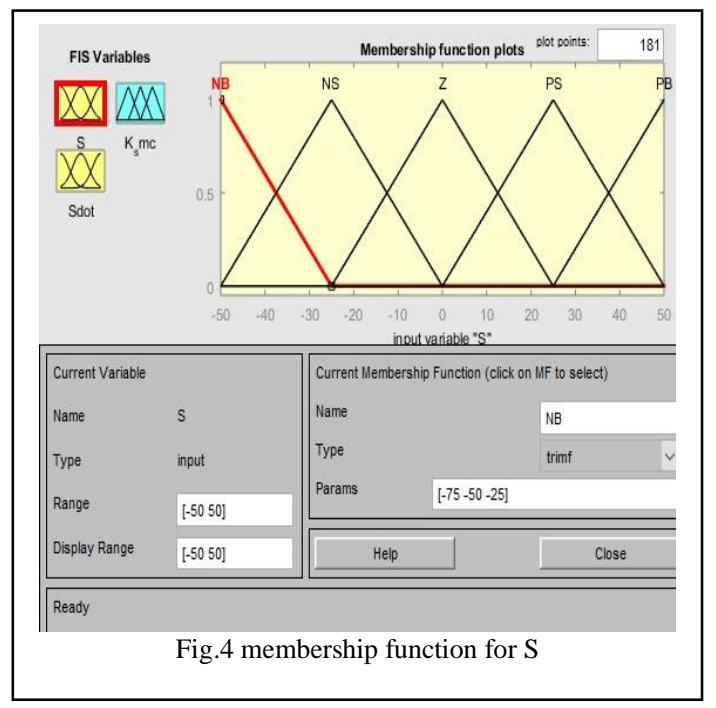

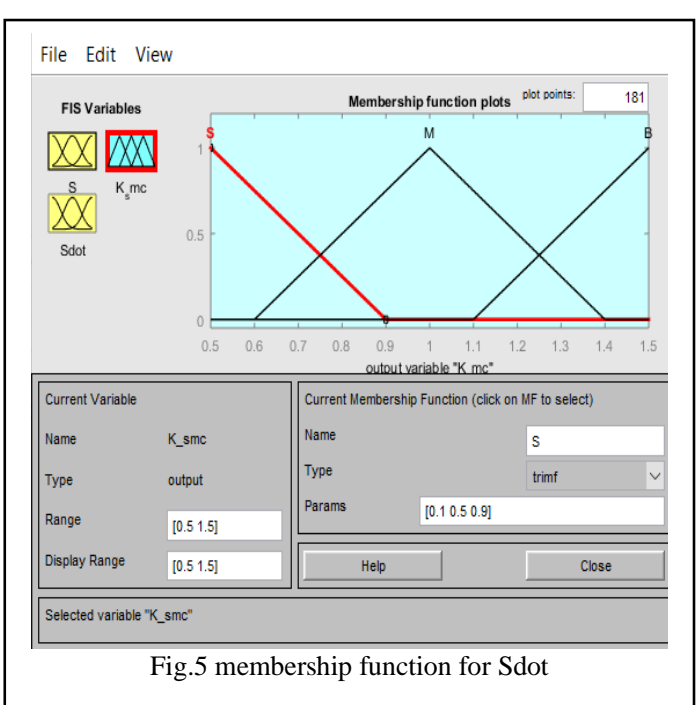

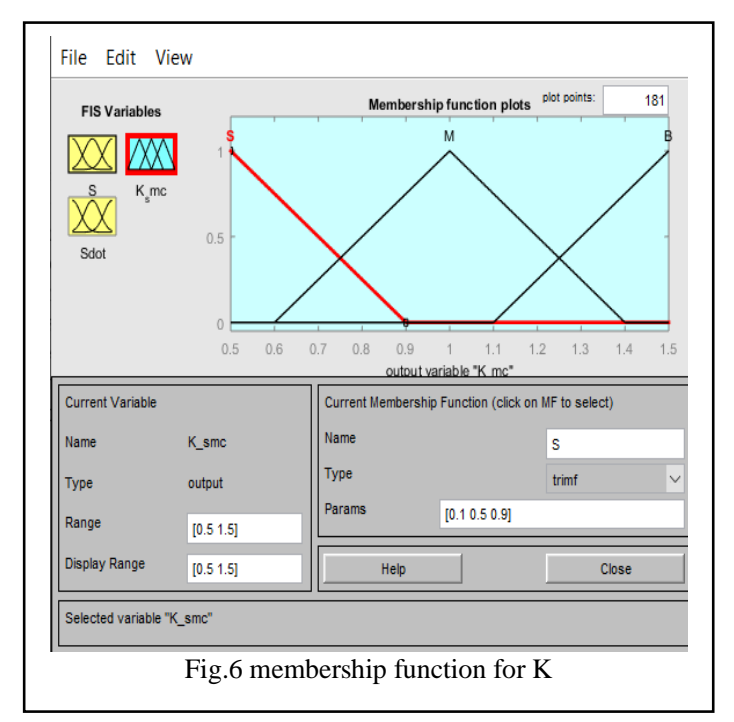

Fig.3 shows how fuzzy system actually works. Input membership functions are given in Fig. $4 \& 5$ while output membership function is given in Fig. 6.

\section{PI CONTROLLER}

PI controller improves only steady state response .It increases type and order of the system. As we increase type of the system steady state error reduces, but due to integrator, response is sluggish and it also reduces system stability.

\section{RESULTS}

For speed control of BLDC motor FUZZYSMC controller is designed in MATLAB/Simulink as shown in Fig 7. And the results are then compared with conventional PI controller. Simulation is done for 10 percent loading, 50 percent loading and full loading. 


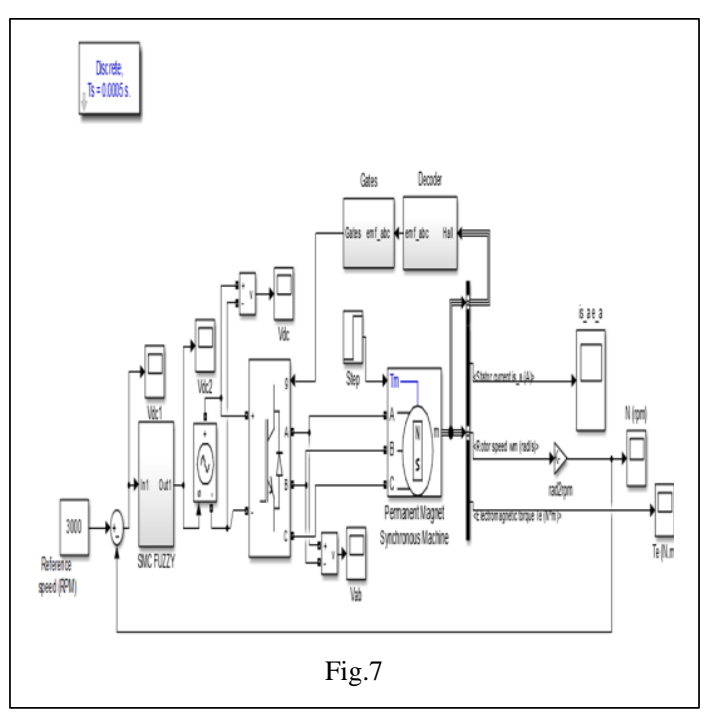

\section{$X$ SPEED PERFORMANCE COMPARISON WITH PI AND FUZZYSMC}

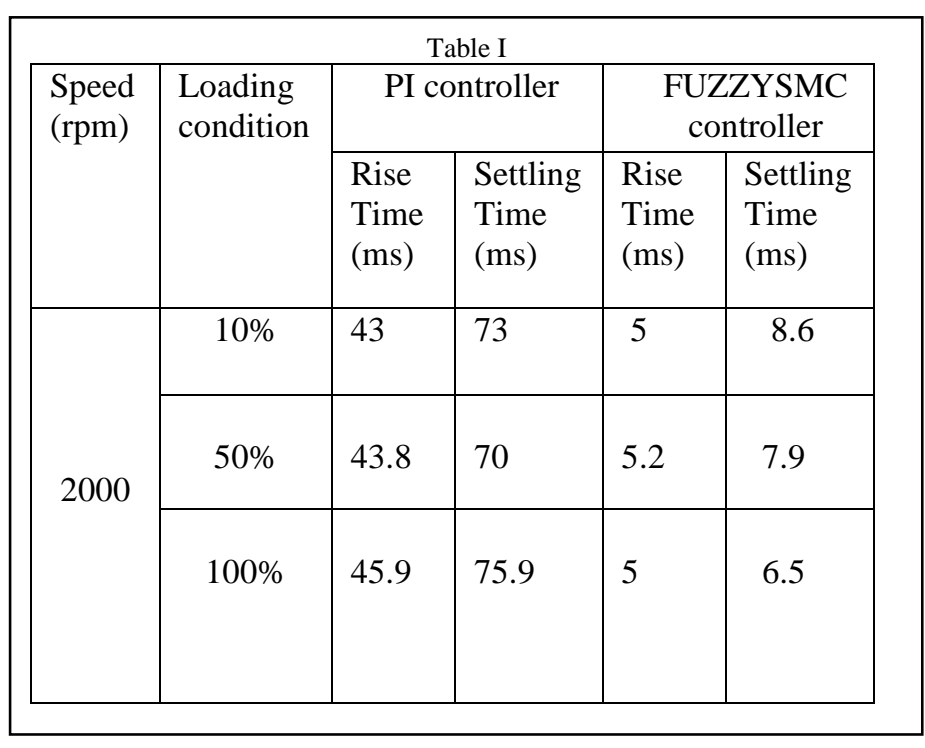
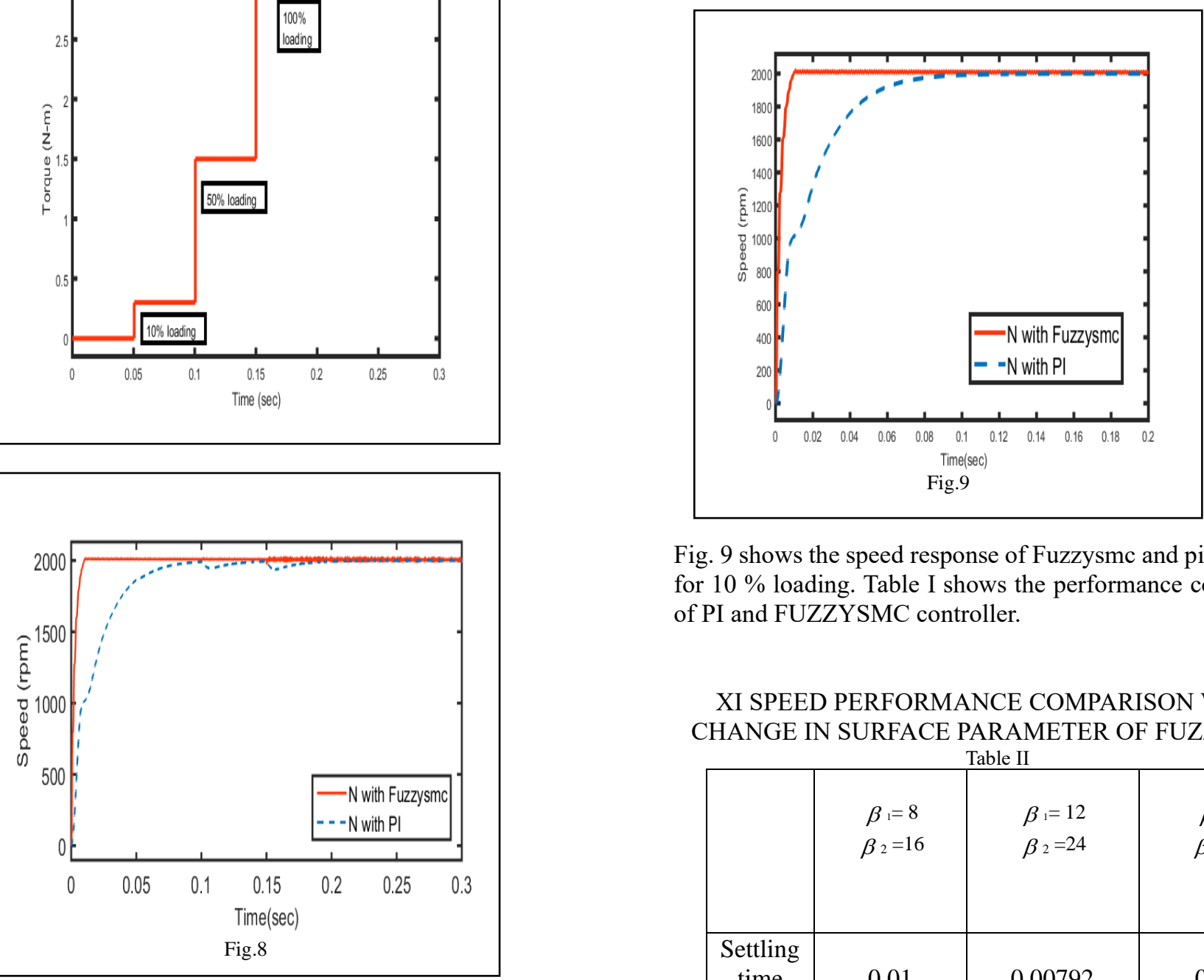

Fig. 9 shows the speed response of Fuzzysmc and pi controller for $10 \%$ loading. Table I shows the performance comparison of PI and FUZZYSMC controller.

XI SPEED PERFORMANCE COMPARISON WITH CHANGE IN SURFACE PARAMETER OF FUZZYSMC

\begin{tabular}{|c|c|c|c|}
\hline & $\beta_{1}=8$ & $\beta_{1}=12$ & $\beta_{1}=5$ \\
& $\beta_{2}=16$ & $\beta_{2}=24$ & $\beta_{2}=10$ \\
\hline $\begin{array}{c}\text { Settling } \\
\text { time }\end{array}$ & 0.01 & 0.00792 & 0.015 \\
\hline
\end{tabular}

Fig. 8 shows speed response of fuzzy logic controller and PI controller for different loading conditions. The system is tested for $10 \%$ loading at 0.05 second, $50 \%$ loading at 0.1 second and $100 \%$ loading at 0.15 second. 


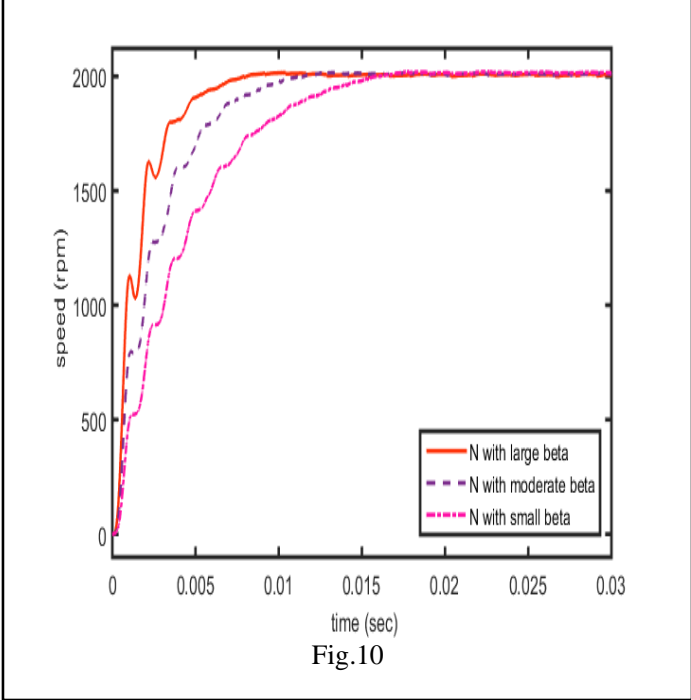

Fig.10 shows speed response of fuzzysmc system for various surface parameters.i.e for small values,for large values and for moderate values and obeservations made acoordingly. Table II shows settling time required for varioue beta values and it is observed that for large values of beta settling time reduces

\section{SPEED PERFORMANCE COMPARISON WITH CHANGE IN PARAMETERS OF PI}

Just like Fuzzysmc, PI parameters are tuned for different values and observation is made that with lesser values of gain parameters better results are obtained.

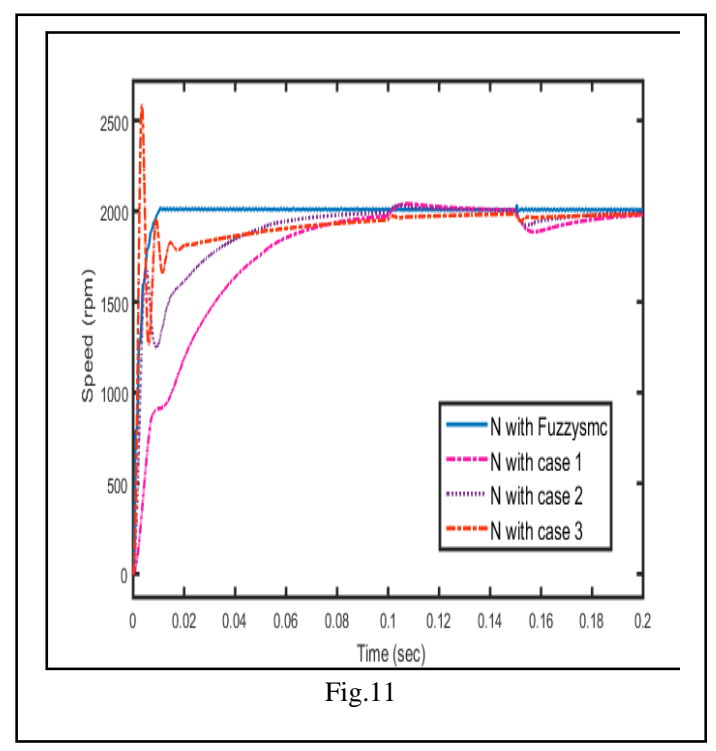

The PI controller is tested for following values:

Case 1 .For $\mathrm{Kp}=0.02, \mathrm{Ki}=4$

Case 2.For $\mathrm{Kp}=0.1, \mathrm{Ki}=8$

Case 3.For $\mathrm{Kp}=0.5, \mathrm{Ki}=10$

\section{CONCLUSION}

FUZZYSMC and PI based controller is implemented to control the speed of BLDC motor. A variable torque is applied and performance of both the controllers is compared. It is observed that rise time and settling time both are less in FUZZYSMC than in PI controller.

\section{REFERENCES}

[1] Pillay, P., and Krishnan, R. "Modeling, Simulation, and Analysis of Permanent-Magnet Motor Drives, Part II:The Brushless DC Motor Drive," IEEE Trans. of Industry Applications, vol. 25, no. 2, pp. $274-279$, March/April 1989

[2] Arun Prasad K.M, Usha Nair "An intelligent fuzzy sliding mode controller for a BLDC motor". International Conference on Innovative Mechanisms for Industry Applications(ICIMIA 2017).

[3] K.S.Krishna Veni, Dr.N.Senthil Kumar J.Gnanavadivel "Low Cost Fuzzy Logic Based Speed Control of BLDC Motor Drives" Ieee International Conference On Advances In Electrical Technology For Green Energy 2017 (Icaetgt' 2k17)

[4] Vimal Nigam, Shoeb Hussain Satya Narayan Agarwal "A Hybrid Fuzzy Sliding Mode Controller for a BLDC Motor Drive "1st IEEE International Conference on Power Electronics, Intelligent Control and Energy Systems (ICPEICES-2016)

[5] Kanaiya Bhatt, Sandip Dhoranwala, Ajay Bosamiya "SIMULATION OF BRUSHLESS DC MOTOR SPEED CONTROL IN MATLAB". International Journal of Advance Engineering and Research Development Volume 4, Issue 12, December -2017

[6] Shivraj Sdudhe, Archana G Thosar. "Mathematical Modelling And Simulation Of Three Phase Bldc motor Using Matlab/Simulink".International Journal of Advances in Engineering \& Technology, Vol. 7, Issue 5, Nov., 2014.

[7] Pramod Pal, TM Shubhum and Dr.Amit Ojha, "Simulation Of Brushless Dc Motor For Performance Analysis Using Matlab/Simulink Environment" International Journal on Recent and Innovation Trends in Computing and Communication Volume: 2 Issue 6

[8] B. Ramesh Mr. P.Ebby Darney, S.Jackulin Gnana Permila “ $A$ Fuzzy Smc Controlled Bldc Motor" International Journal of Innovative Works in Engineering and Technology (IJIWET) ISSN: 2455-5797

[9] V.I.Utkin, "Sliding mode control design principles and applications to Electric drives,"IEEE Transactions on Industrial Electronics, vol.40, no.1, pp.23-26, February 1993.

[10] "Digital control and state variable methods"by Mr.M Gopal.

[11] "Fundamentals of electric drives" by G.K.Dubey

[12] Ali Mousmi, Yassine el Houm, Ahmed Abbou "Implementation of a Fuzzy logic controller for a BLDC motor"

[13] "Electrical drives" by Mr.S.K.Pillai.

[14] M.V.Ramana Rao,P.V.N.Prasad "Modelling and Implementation of Sliding Mode Controller for PMBDC Motor Drive."International journal of advanced research in electrical,electronics and instrumentation engineering.vol.3,Issue 6,june 2014.

[15] K.S.krishna Veni,Dr.N.Senthil Kumar,J Gnanavadivel "Low Cost Fuzzy Logic Based Speed Control of BLDC Motor Drives"IEEE International Conference on advances in electrical technology for green energy 2017.

[16] P.Sowjanya,Dr.S.Tarakalyani "PI and SMC for Permanent Magnet Brushless DC Motor.International Journal of Innovative Technology And Reseach Volume no.1,issue no.5,AugustSeptember 2013,497-502. 